\title{
O pensar e o agir de profissionais de saúde sobre a coordenação entre os níveis assistenciais da rede de atenção à saúde
}

\author{
The thinking and acting of health professionals on the coordination \\ between the assistance levels of the health care network
}

Mireilly Cristiany Moura Hemetério Araujo (https://orcid.org/0000-0002-1593-1575) ${ }^{1}$

Lygia Carmen de Moraes Vanderlei (https://orcid.org/0000-0002-3610-3699) ${ }^{1}$

Marina Ferreira de Medeiros Mendes (https://orcid.org/0000-0002-5752-5217) ${ }^{1}$

Paulo Germano de Frias (https://orcid.org/0000-0003-4497-8898) ${ }^{1}$

${ }^{1}$ Instituto de Medicina Integral Prof. Fernando Figueira. R. dos Coelhos 300, Boa Vista. 50070-

550 Recife PE Brasil.

mireilly17@yahoo.com.br

\begin{abstract}
The study aims to understand the thinking and acting of health professionals about the coordination between levels of care. Qualitative research from an international multicenter study Equity-LA II. Audios were retrieved from eleven interviews of doctors/nurses of two levels of care in Recife, 2014. A content analysis of the theoretical framework of coordination was performed in the light of the hermeneutic approach. Most professionals knew the duties of coordination, without identifying its execution. The primary care physician was not recognized as responsible for the clinic, nor for his role by the specialist physician, while the primary care physician resented it. Failures in the use/completion of reference/counter-reference mechanisms and organizational barriers emerged. The unavailability for the "conversation game" and "fusionality" was evidenced in the lack of recognition of authority in the authoritative character of the primary care physician by that of the specialized, feeling of less value for that and technicist and specialized posture in everyone's practice. The coordination in on professionals' view revealed the "there-to-be-understood" condition that needs to be launched in the "game of comprehension" to build dialogical practices focused on integral care.
\end{abstract}

Key word Health Care Levels, Clinical Management, Hermeneutics, Qualitative Research
Resumo O estudo objetiva compreender o pensar e o agir dos profissionais de saúde sobre a coordenação entre níveis assistenciais. Pesquisa qualitativa oriunda de estudo multicêntrico internacional Equity-LA II. Reescutaram-se áudios de onze entrevistas de médicos/enfermeiras de dois niveis assistenciais no Recife, 2014. Realizou-se análise de conteúdo do referencial teórico da coordenação à luz da abordagem hermenêutica. A maioria dos profissionais conhecia as atribuições da coordenação, sem identificar sua execução. O médico da atenção primária não foi reconhecido como responsável clínico, nem quanto ao seu papel pelo médico da atenção especializada, enquanto o da atenção primária ressentia-se. Emergiram falhas no uso/preenchimento dos mecanismos de referência/contrarreferência e entraves organizacionais. A indisponibilidade para o "jogo da conversação" e "fusionalidade" evidenciou-se no não reconhecimento da autoridade no caráter autoritativo do médico da atenção primária pelo da especializa$d a$, sentimento de menos valia daquele e postura tecnicista e especializada na práxis de todos. A coordenação no olhar dos profissionais revelou a condição "aí-a-ser-compreendido" carecendo se lançar no "jogo da compreensão" para construir práticas dialógicas voltadas ao cuidado integral.

Palavras-chave Niveis de Atenção à Saúde, Gestão Clínica, Hermenêutica, Pesquisa qualitativa 


\section{Introdução}

As experiências iniciais de sistemas integrados de saúde induziram a constituição de Redes de Atenção à Saúde (RAS) que se disseminaram na

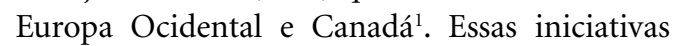
buscaram romper a segmentação dos sistemas nacionais de saúde e a fragmentação do processo de cuidado, como estratégia de enfrentamento à ineficiência e baixa qualidade na atenção aos usuários ${ }^{2}$.

São poucos os países com sistemas públicos universais, a exemplo da Espanha e Reino Unido, que com variações privilegiam o acesso pleno, equidade, integração, regionalização e hierarquização da rede ${ }^{1,3,4}$. No Brasil, apesar dos inegáveis avanços, o sistema de saúde segue fragmentado e direcionado aos adoecimentos agudos e crônicos agudizados, reafirmando a necessidade da organização em RAS ${ }^{5,6}$.

As RAS são arranjos formados por serviços e ações, com conformações tecnológicas e atribuições diversas, organizadas complementarmente. Entre suas principais características se destacam a responsabilização sanitária por atenção contínua e integral; o compartilhamento de objetivos; a centralidade nas necessidades de saúde da população tendo a Atenção Primária à Saúde (APS) como centro de comunicação e ordenadora do cuidado; e relações horizontais entre os pontos de atenção e o cuidado multiprofissional ${ }^{7}$.

No Brasil as dificuldades para a implementação das RAS relacionam-se aos escassos recursos aliados ao desequilíbrio financeiro entre a APS e a Atenção Especializada (AE); a disponibilidade; a formação e os vínculos dos profissionais e as iniquidades regionais ${ }^{6,8}$. A APS como ordenadora do cuidado longitudinal, necessita compartilhar incumbências entre os médicos do seu nível de atenção, responsáveis clínicos pelo paciente, e os da $\mathrm{AE}^{5,9}$.

A coordenação refere-se à conexão harmoniosa entre diferentes serviços e níveis de atenção com sincronização de procedimentos destinados ao usuário necessários ao seu cuidado contínuo, na obtenção de objetivos comuns, sem conflitos e articulados. Uma melhor integração na RAS atrela-se ao maior sucesso da coordenação assistencial, existindo determinantes organizacionais, profissionais e de necessidades em saúde do usuário, que influenciam a colaboração e responsabilidade entre a APS e a $\mathrm{AE}^{10-12}$.

Para investigar a coordenação entre níveis assistenciais existem várias abordagens, como a utilizada em pesquisa multicêntrica para avaliar estratégias de melhoria e qualidade assistencial nas RAS da América Latina (Equity-LA II) ${ }^{13}$, que considera três tipos de coordenação: informação, gestão clínica e administrativa ${ }^{14}$. Entretanto, análises sob uma perspectiva teórica compreensiva não são usuais, como a hermenêutica filosófica, que interpreta o sentido atribuído pelo ser e pela compreensão da ciência como um discurso, caracterizada pela busca de validação intersubjetiva, embasada pelo compromisso com a verdade, que envolve incertezas e se produz na relação sujeito-objeto ${ }^{15-18}$.

Nessa concepção, a verdade é uma experiência hermenêutica que remete à revelação no encontro entre o familiar e o desconhecido, resultante de construções socio-históricas e culturais (tradição, preconceitos, horizonte) $)^{15,16}$. A coordenação assistencial ocorreria numa relação dialógica, intersubjetiva, reflexiva, caracterizada pela "boa prática" ${ }^{15,18}$, alcançada quando dois entes dialogam se entendendo sobre algo, mesmo sem concordar com a visão um do outro, mas se colocando em contato com o horizonte do outro. Assim, a construção da verdade é uma experiência aberta à ressignificação, que requer a mediação entre o conhecimento técnico-científico e o saber ser sobre ele mesmo ${ }^{16,19}$.

A compreensão dos fenômenos implica em desvelar qual o sentido conferido pelos atores que os compõem, identificados pelos profissionais enquanto autoridade, que constituem e são constituídos pelos serviços de saúde, procedimentos, processos e pelos outros com os quais se relacionam. Esses, expressam a legalidade do horizonte da tradição desse saber engendrado de pressupostos e preconceitos que caracteriza sua ação ${ }^{16,17,19}$. O objetivo do artigo é compreender o pensar e o agir dos profissionais sobre a coordenação do cuidado entre níveis assistenciais.

\section{Métodos}

Pesquisa avaliativa de abordagem qualitativa, cujos referenciais teóricos acerca da coordenação entre níveis de atenção à saúde ${ }^{14}$ foram articulados aos da hermenêutica filosófica ${ }^{15,19}$.

A investigação foi um recorte da vertente qualitativa da linha de base da Pesquisa Equity-LA $\mathrm{II}^{13}$, que analisou as dimensões da coordenação de informação (transferência da informação clínica e biopsicossocial; da coordenação de gestão clínica (seguimento adequado do paciente, acessibilidade entre níveis e coerência da atenção) e da coordenação administrativa (circuitos admi- 
nistrativos estabelecidos e ordenação do acesso). Os critérios de elegibilidade para selecionar os informantes foram: médicos e enfermeiros atuando há pelo menos seis meses na APS e AE, este último que atendesse em centros especializados de referência ao atendimento a pacientes com enfermidades crônicas e que aceitassem participar da pesquisa.

No presente estudo utilizaram-se os áudios de onze entrevistas semiestruturadas, mediante roteiro construído a partir do marco teórico da coordenação ${ }^{14}$, aplicadas aos médicos (três da APS e cinco da AE) e enfermeiras (duas da APS e uma da AE) no Recife, nos anos de 2014 e 2015.

O material empírico foi analisado para se compreender os sentidos expressos no discurso dos participantes a partir da interpretação hermenêutica $^{15,19}$, considerando o pesquisador como um sujeito implicado na pesquisa e que esta ação é feita em um contínuo relacional, a partir do diálogo interpretativo, ainda que a totalidade compreensiva não possa ser plenamente alcançada pelos limites inerentes ao percurso metodológico em tela, que dificultaram o processo de intersubjetividade dos atores que a compuseram.

Realizou-se a análise de conteúdo, um processo sistemático, compreensivo, interativo e cíclico ${ }^{20}$ desenvolvida em três fases: 1) pré-análise do material através de reescutas dos áudios das entrevistas, para realizar a análise do discurso dos atores, inclusive características paralinguísticas, com registros de silêncios, risos e elementos de interesse analíticos; 2) leitura compreensiva das novas transcrições para aproximação do todo de cada relato e do seu conteúdo latente; seguiu-se à organização do material, com identificação das informações e separação de conjuntos dos discursos segundo características dos atores (idade, sexo, etc); unidades gramaticais (frases ou parágrafos); por evolução temporal da narração ou por combinação de vários destes aspectos; 3 ) elaboração de categorias empíricas ou unidades de sentido, resultantes da identificação de padrões, dados relacionados entre si, correspondentes a um tema determinado, criadas de maneira indutiva decorrente da reescuta dos áudios, dos roteiros das entrevistas e/ou da combinação de ambos (Quadro 1).

A análise foi realizada da primeira à terceira fase em cada uma das entrevistas e comparativamente entre os atores por níveis de atenção, para o estabelecimento de dissensos, contradições e consensos emergentes. Finalmente efetuaramse a descrição e interpretação dos resultados, o estabelecimento de relações e desenvolvimento de explicações e/ou hipóteses constituintes do marco teórico gadameriano que permitiram a atribuição de sentido aos achados possibilitando assim com que o jogo da compreensão/interpretação ocorresse.

A definição do tamanho da amostra foi feita por saturação, que se relaciona aos critérios de conveniência-pertinência, e versam sobre a qualidade e suficiência da informação, quando seu conjunto apresenta completude para alcançar os objetivos da pesquisa e expressa saturação, caracterizada por redundância e ausência de aspectos novos nos discursos, evidenciando seu esgotamento $^{20}$. Os informantes foram apresentados por códigos que garantiram a confidencialidade e a procedência da informação.

O estudo seguiu os princípios éticos, segundo a Resolução no 466/2012 do Conselho Nacional de Saúde e foi aprovado pelo Comitê de Ética em Pesquisa em Seres Humanos do Instituto de Medicina Integral Prof. Fernando Figueira.

\section{Resultados}

A amostra foi composta por 11 informantes, dez mulheres e um homem, sendo da APS duas enfermeiras, duas médicas e um médico e da $\mathrm{AE}$, uma enfermeira e cinco médicas; idades entre 45 e 68 anos; experiência no serviço entre um e 19 anos; dez desses profissionais com residência ou especialização. A exposição seguiu a ordem de emersão das categorias/subcategorias comparativamente entre os níveis assistenciais onde os atores trabalhavam.

Quase todos os participantes conheciam as atribuições da coordenação, sem identificar sua execução na rede. Os discursos nos dois níveis assistenciais revelaram o não reconhecimento do médico da APS como responsável clínico. Destacaram-se falhas no uso e preenchimento dos mecanismos de referência/contrarreferência e inexistência de outros, como reuniões clínicas e entraves organizacionais.

\section{Aspectos relacionados à organização entre níveis assistenciais de saúde}

Pouco mais da metade dos profissionais desconhecia os termos responsável clínico, gestão clínica e administrativa e coordenação da informação; alguns os confundiam com atribuições da gestão ou não referiam adequadamente as ações desempenhadas (Quadro 2). 


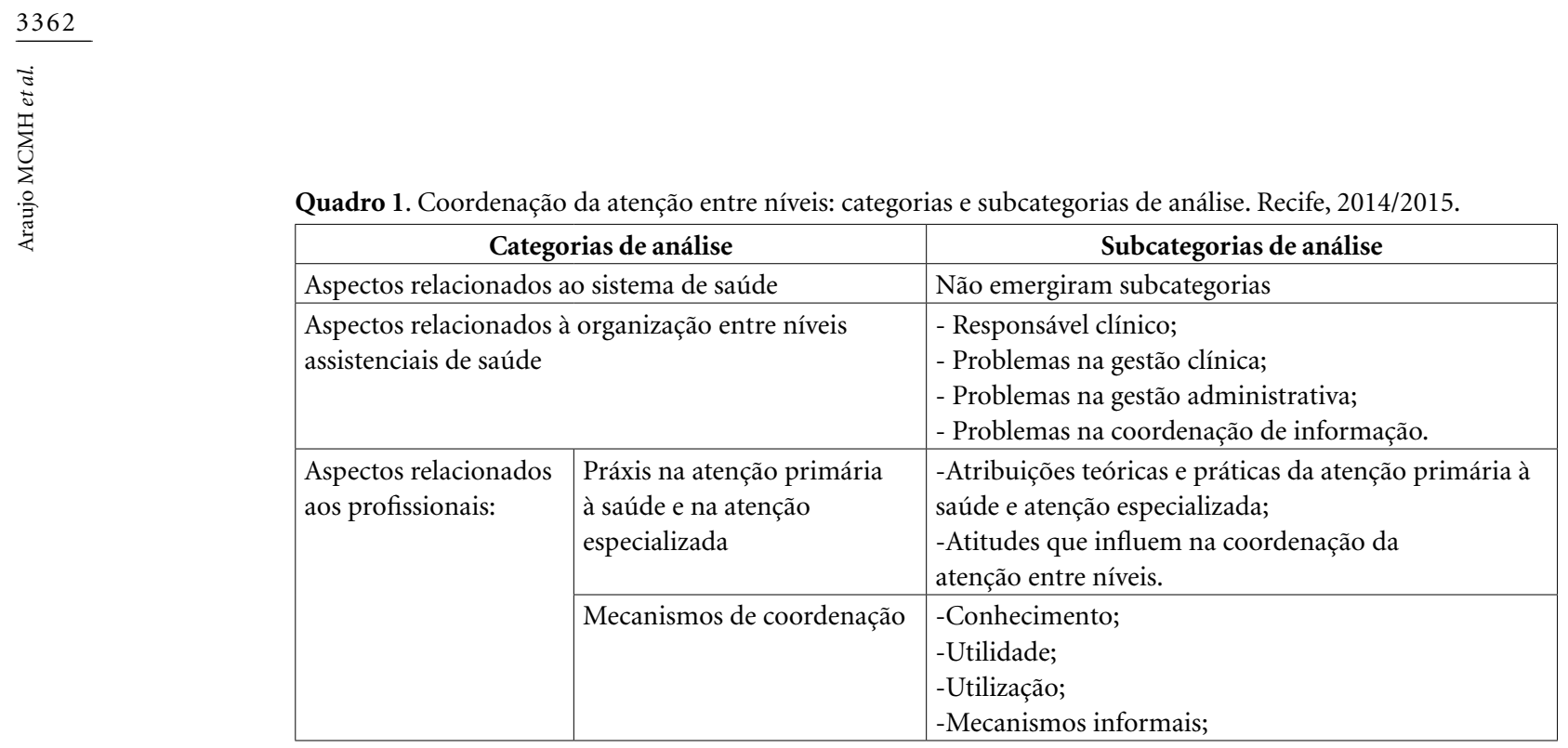

Fonte: Modificada do marco teórico da pesquisa Equity-LA II ${ }^{13}$.

\section{Responsável clínico}

Mesmo com o reconhecimento do médico da APS como responsável clínico por dois médicos deste nível e três da $\mathrm{AE}$, só um de cada nível assistencial conhecia o conceito e sua importância para o desenvolvimento adequado da atenção, apesar de mencionarem que essa função não era desenvolvida na rede de saúde.

Uma enfermeira da APS atribuiu à equipe da ESF o papel de responsável clínico e dois médicos da AE conheciam o termo, mas não o identificaram como sendo o médico da APS.

\section{Problemas na Gestão clínica}

Quatro médicos da AE relataram problemas na gestão clínica pelos encaminhamentos inadequados da APS, implicando em deslocamentos inúteis dos usuários e ocupação desnecessária de vagas.

\section{Problemas na Gestão administrativa}

Todos os profissionais entrevistados apontaram aspectos organizacionais que dificultavam a coordenação entre níveis, emergindo frequentemente falhas na marcação de consultas, insuficiência de vagas, de equipamentos e de profissionais nos dois níveis assistenciais, ocasionando sobrecarga dos profissionais e longa espera por assistência, especialmente a especializada.

O Sistema Nacional de Regulação (Sisreg) foi apontado recorrentemente entre todos os atores como instrumento organizativo que dificultava a coordenação entre níveis por inadequada operacionalização, ainda que uma enfermeira da APS o percebesse promissor.

A desproporcionalidade entre demanda da população e oferta de consultas e exames tam- bém emergiu uniformemente entre entrevistados dos dois níveis. Na visão dos profissionais da $\mathrm{AE}$ isso contribui para diminuir o tempo das consultas, comprometendo a qualidade, o registro adequado e a contrarreferência.

Problemas na Coordenação da informação

Emergiram na fala de quatro médicos da $\mathrm{AE}$ problemas de não informação correta do perfil da unidade referenciada, resultando em encaminhamentos equivocados para centros especializados. Para um médico da APS os problemas devem-se à falta de comunicação entre os níveis assistenciais.

\section{Aspectos relacionados aos profissionais: práxis na atenção primária à saúde na atenção especializada}

\section{Atribuições teóricas e práticas da APS e AE}

A maioria dos profissionais demonstrou conhecer o papel da APS como ordenadora do cuidado, abordando a responsabilidade sanitária compartilhada no território (família, aspectos sociais e culturais). Nem sempre as falas foram claras ou seguras, existindo pausas para sua expressão, apontando restrições ao desempenho desse papel, com queixas nas relações interpessoais, administrativas e organizacionais (Quadro 3).

Dentre os que desconheciam o papel da APS, as falas restringiram sua função ao controle da doença, enfatizando a intervenção médica para evitar a piora. Houve consenso entre os informantes sobre a atuação de o especialista ser de suporte e continuidade do cuidado para os casos de maior complexidade. 
Quadro 2. Aspectos relacionados à organização entre níveis assistenciais de saúde. Recife, 2014/2015.

\begin{tabular}{|c|c|}
\hline $\begin{array}{c}\text { Categorias/ } \\
\text { subcategorias }\end{array}$ & Citações \\
\hline $\begin{array}{l}\text { Responsável } \\
\text { clínico }\end{array}$ & $\begin{array}{l}\text { "se existisse um clínico para poder gerenciar esses encaminhamentos de especialidade acho que } \\
\text { reduziria muito a quantidade de consultas desnecessárias. [...] evitaria que o especialista ficasse } \\
\text { investigando uma coisa que já era para [...] aprofundar o tratamento dele [paciente]" (M7-AE). } \\
\text { "Olhe [...] na maioria dos casos, ou seja, 85-90\% deveria ser o médico da assistência básica, [...], o } \\
\text { responsável por tudo isso" (M2-APS). } \\
\text { "Eu acho que o responsável mesmo seria o da APS, porque ele vai ver o paciente como um todo. vai } \\
\text { receber as informações das outras especialidades que forem necessárias" (M4-AE). } \\
\text { "Veja a gente aqui [...], no PSF a gente sempre trabalha em equipe, a gente não tem isso de [...] } \\
\text { Assim, o médico dá o diagnóstico, mas ele precisa do NASF, ele precisa da gente, das enfermeiras, } \\
\text { dos técnicos, dos dentistas [...] Um atendimento, ele não é um paciente do médico, ele é um } \\
\text { paciente de todos nós" (E2-APS). }\end{array}$ \\
\hline & $\begin{array}{l}\text { "Sinceramente, eu não sei [...] Um grande número de pacientes não traz exame nenhum. } \\
\text { [...] eles dizem que não foi nem solicitado.... Outros, o médico [APS] solicita para fazer o } \\
\text { acompanhamento lá, e, quando, não sei quem consegue o encaixe para cá [AE], o exame não foi } \\
\text { nem feito, porque... ele seria visto pelo profissional de lá [APS] que já acompanha direitinho [...]. } \\
{[\ldots . . \text { é completamente embaralhado... Assim, tu pergunta como é a coordenação? realmente [...] }} \\
\text { não faço a mínima idéia! Porque é tudo descoordenado [...] É desarrumado mesmo, não tem" } \\
\text { (M6-AE). } \\
\text { "[...] eu noto que há coisas que tem que ter [...] uma harmonia muito completa entre a medicina } \\
\text { básica e a... mais específica [...] E teria que funcionar em vários pontos, não adianta um só } \\
\text { funcionar e o outro não..., aí gera uma dificuldade grande porque começa a descaracterizar o } \\
\text { serviço. O serviço que funciona, passa a absorver tudo e começa a descaracterizar o papel que ele } \\
\text { começou" (M7-AE). }\end{array}$ \\
\hline $\begin{array}{l}\text { Problema } \\
\text { na gestão } \\
\text { administı }\end{array}$ & $\begin{array}{l}\text { "Porque eles [pacientes] estão tendo muita dificuldade de marcação de exames...temos pacientes } \\
\text { demorando meses para conseguir fazer" (E1-APS). } \\
\text { "O problema é que o resultado (do exame) demora muito. Às vezes demora assim, às vezes um } \\
\text { mês, tem paciente aqui que já veio buscar não sei quantas vezes e não conseguiu”" (E3-AE). } \\
\text { "[...] eles [gestores] teriam que enxugar o [Centro Especializado]. Vamos pegar esses pacientes e } \\
\text { entregar na atenção primaria! Eles não fazem isso, os pacientes hipertensos lá [AE] drogas que o } \\
\text { médico [APS] pode prescrever. [...] tem que pegar pacientes que realmente precisem de endócrino, } \\
\text { com diabetes complicados [...] a gestão é para isso...tem que estar unindo secundaria com } \\
\text { primaria, [...] a gestão também é culpada se não existe isso... e a gente não pode chegar e pedir ao } \\
\text { colega: ô vamos marca reunião" (M1-APS). } \\
\text { "[...] acho que isso tudo foi feito antes. Certinho, a gente viu a comunicação e suspenderam isso. } \\
\text { Politica da prefeitura, não foi a gente não. [...] Foram extintos os postos que eles (pacientes) } \\
\text { podiam ser atendidos... agora não conseguem marcar, então por isso essa grande demanda para } \\
\text { cá... [Centro Especializado]" (M8-AE). } \\
\text { "[...] Então assim, é uma sobrecarga muito grande, o sistema [Sisreg], as vagas que disponibiliza } \\
\text { lá não da conta é uma única funcionaria para isso, [...] tem um monte de pastas e de pacientes } \\
\text { de seis, sete meses para especialista [...]. Existe uma clientela muito grande, então, que usa essa } \\
\text { pequena cota de exames" (E1-APS). } \\
\text { "[...] a gente já vem com um número de pacientes fixo grande. E está aumentando e o número de } \\
\text { médico não aumenta. [...] Nem de enfermagem para dar esse apoio a gente” (M5-AE). } \\
\text { "Chegou agora o Sisreg ... para regular a nossa referência. E como eu chamo, às vezes é uma, uma } \\
\text { fila virtual,... mas, eu acho que tem melhorado, ela ainda não é perfeita, para mandar para o } \\
\text { especialista às vezes você demora dois, três, cinco, quatro, seis meses,....”" (E2-APS). }\end{array}$ \\
\hline $\begin{array}{l}\text { Problemas na } \\
\text { coordenação } \\
\text { de informação }\end{array}$ & $\begin{array}{l}\text { "[...] eles encaminham às vezes com [...] o que tem de contato, a historinha do paciente e a } \\
\text { intercorrência que ela está sentindo, "paciente tá precisando controlar melhor a pressão, está } \\
\text { com os pés inchados". Essas coisas ela [APS] dá, desse encaminhamento informando é o que tem. } \\
\text { Basicamente isso" (M5-AE). } \\
\text { "Não existe comunicação [...] Só quando a gente manda para um colega conhecido, [...] é meu } \\
\text { amigo aí eu mandei ele me dar um retorno, mas quando a gente manda tudo no papelzinho } \\
\text { bonitinho não" (M1-APS). }\end{array}$ \\
\hline
\end{tabular}

Nota: APS: Atenção Primária; AE: Atenção Especializada; NASF: Núcleo de Apoio à Saúde da Família; PSF: Programa de Saúde da Família. 
Nenhuma das falas expressou a ação compartilhada entre os níveis, a maioria mostrou compreensão restrita quanto ao papel da $\mathrm{AE}$, redu- zindo-o ao diagnóstico, solicitação de exames e tratamento medicamentoso, não abordando sua responsabilidade com a orientação aos usuários e

Quadro 3. Aspectos relacionados aos profissionais: práxis na atenção primária à saúde e na atenção especializada. Recife, 2014/2015.

\begin{tabular}{|c|c|}
\hline $\begin{array}{c}\text { Categorias/ } \\
\text { Subcategorias }\end{array}$ & Citações \\
\hline $\begin{array}{l}\text { Atribuições } \\
\text { teóricas e } \\
\text { práticas da } \\
\text { APS e AE }\end{array}$ & $\begin{array}{l}\text { "[...] eu acho que a gente [APS] consegue um controle muito bom dos pacientes em mais de 90\% } \\
\text { deles, com orientações higiênico-dietéticas, de mudança de estilo de vida, até de medicação mesmo, } \\
\text { a gente consegue controlar bem, cerca de } 90 \% \text { deles" (M3-APS). } \\
\text { "O papel da APS [...] início dar educação para todos, pacientes e familiares, já que você consegue } \\
\text { abranger as pessoas, consegue chegar até ir na casa da pessoa para ver as condições que ela mora, } \\
\text { as condiçóes que teria de seguimento e fazendo uma fiscalização maior [...] atendimento médico } \\
\text { [...] e um atendimento inicial [...] rastreamentos de complicações podia [...] ser todo feito na APS" } \\
\text { (M6-AE). } \\
\text { "[...] dar os primeiros cuidados para pacientes e, no momento que [...] passem a apresentar } \\
\text { alguma complexidade maior e observe que não tem estrutura para fazer o acompanhamento deles } \\
\text { naquele serviço eles (APS) encaminham para o serviço que tenha uma estrutura maior para poder } \\
\text { absorvê-los" (M7-AE). } \\
\text { "[...] É necessário [AE] [...] Depois, quando a diabetes está muito avançada que deixa as sequelas, } \\
\text { que o paciente não se cuidou" (E1-APS). } \\
\text { "Atualmente, eu acho que a gente tem um grande problema [...] você tem pacientes às vezes } \\
\text { que não teriam tanta necessidade de estarem sendo acompanhados por especialistas [...] estão } \\
\text { ocupando digamos assim, a vaga de um paciente de difícil tratamento [...]" (M3-APS). } \\
\text { "[...] grande maioria que vem para cá, que é encaminhado da rede, não teria indicação, [...] } \\
\text { de estar aqui. [...] ele [médico da APS] manda, a impressão que dá para gente, é que está } \\
\text { superlotado lá, ele quer se livrar do máximo paciente possivel, [...] É meio, "passa adiante mesmo". } \\
\text { Porque ouve dizer que aqui é muito bom [o paciente], [...] e está tudo controladinho, tinha nem } \\
\text { indicação..." (M6-AE). } \\
\text { "...eu não vou devolver o doente, do ponto de vista do diabetes ele é meu agora... Ele fica com } \\
\text { a gente. Num foi encaminhado? É como se, na minha opinião, lá [na APS] não estavam } \\
\text { conseguindo compensar o doente e mandou pra cá, então eu vou ficar acompanhando" (M8-AE). }\end{array}$ \\
\hline $\begin{array}{l}\text { Atitudes que } \\
\text { influem na } \\
\text { coordenação } \\
\text { da atenção } \\
\text { entre níveis }\end{array}$ & $\begin{array}{l}\text { "[...] aquilo que eu costumo chamar e que algumas pessoas criticam que éo "médico ao ao", aquele } \\
\text { médico que atende e só faz encaminhar ao dermatologista, ao cardiologista, ao clínico, ao pediatra, } \\
\text { [...], quando na realidade ele teria que resolver [...]" (M2-APS). } \\
\text { "[...] questão de preparo ou capacitação dos médicos para receberem os pacientes e realmente só } \\
\text { encaminhar as dúvidas [...]. Que muitas vezes esses pacientes novos [...], uns não tem nada a ver } \\
\text { com hanseníase, passam longe [...] depende muito da sua capacidade técnica e tal" (M4-AE). } \\
\text { "o paciente não gosta do médico [...] na APS, então por isso ele não vai no grupo de hipertenso } \\
\text { e diabético, então ele não se trata aqui, então ele vai procurar em outro lugar, onde é que ele vai } \\
\text { procurar? No especialista" (M3-APS). } \\
\text { "[...] desde que, a gente tivesse o cuidado quando faz o encaminhamento, encaminhar com } \\
\text { consciência [...] e uma coisa bem legível [...] e que o colega tivesse também a delicadeza de ler } \\
\text { o encaminhamento, [...]. e fazer sua referência da mesma maneira [...] que melhoraria muito" } \\
\text { (M2-APS). } \\
\text { "Às vezes o pessoal do PSF faz muito o geral, muito [...] superficial, aí quando encaminha para } \\
\text { gente, a gente acaba tendo necessidade de também fazer uma orientação que poderia ter sido lá, } \\
\text { pela enfermagem, pelo agente de saúde [...]. Porque às vezes o paciente vem muito desorientado } \\
\text { [...] A APS é que tem que ter essa integração de orientar melhor o paciente, e não o especialista" } \\
\text { (M5-AE). } \\
\text { "[...] esses dois pacientes [diabético e com DPOC], eles têm que ter muita mudança de } \\
\text { comportamento. Então a gente tem a dificuldade de fazer entender, de fazer aceitar, de criar essa } \\
\text { modificação de comportamento" (E2-APS). }\end{array}$ \\
\hline
\end{tabular}

Nota: APS: Atenção Primária; AE: Atenção Especializada; PSF: Programa de Saúde da Família; DPOC: Doença pulmonar obstrutiva crônica. 
informações à APS, constituindo-se na visão de todos os profissionais da APS um obstáculo para a atenção.

Todos os atores dos dois níveis informaram o não cumprimento das suas funções adequadamente, concordando quanto ao excesso de usuários atendidos ser superior ao preconizado, acarretando sobrecarga e superlotação.

Todos os informantes revelaram insatisfação com o desempenho das redes, com acusações e críticas entre os níveis. As recriminações mútuas referiram-se à falta de compromisso dos profissionais e interferência negativa pelo não cumprimento adequado dos papéis correspondentes, não reconhecimento de competência técnica da APS pela AE, barreiras no acesso aos especialistas devidas às falhas do Sisreg, levando a busca informal de acesso à AE.

\section{Atitudes que influem na coordenação da atenção entre níveis}

Emergiram contrariedades nas falas de três médicos da APS pelo desrespeito dos colegas da $\mathrm{AE}$ por não considerarem ou lerem seus encaminhamentos, enquanto todos os especialistas se queixaram de equívocos dos colegas da APS tanto nas referências quanto nos procedimentos.

Outra dificuldade à coordenação entre níveis apontada por três médicos e uma enfermeira da APS foi a indisponibilidade dos profissionais da AE para a orientação dos casos que necessitam de cuidado conjunto, enquanto para todos os especialistas este problema é devido ao não cumprimento adequado da função do médico da APS, repassando casos não complexos para o nível secundário. Para os especialistas isso seria uma alternativa para os médicos da APS lidarem com a elevada demanda no serviço ou por insuficiente conhecimento técnico para a realização das suas tarefas.

Um médico da APS apontou falta de preocupação dos colegas do mesmo nível de atenção quanto ao compromisso e responsabilidade clínica na investigação e resolutividade das demandas dos usuários, acarretando seu desconforto, irritação e descontentamento.

Foram relatadas por todos os profissionais da AE falhas da APS nas ações de promoção e prevenção, em contraposição, três médicos e uma enfermeira da APS identificaram resistência dos pacientes para mudar o estilo de vida e falta de identificação com o profissional deste nível. Para uma médica da APS existe inabilidade do profissional deste nível no vínculo adequado com o usuário ao não considerar aspectos biopsicosso- ciais na prestação do cuidado, ocasionando sua busca pela AE.

A crítica a pouca competência técnica do médico da APS na utilização do formulário da referência surgiu na fala de cinco especialistas e um médico do mesmo nível, que destacou a importância de encaminhamentos "bem-feitos e com letra legível”.

As condições de trabalho, entendidas como "estrutura" por um médico da AE, foram apontadas como entrave pelas equipes da APS, impelindo-as a encaminhamentos equivocados para a rede especializada.

\section{Aspectos relacionados aos profissionais: mecanismos de coordenação}

\section{Conhecimento}

Todos os entrevistados conheciam os formulários de referência e contrarreferência como instrumento preconizado para a comunicação entre níveis, outros mecanismos foram citados apenas por dois médicos da APS, a reunião clínica, a equipe matricial (Nasf), o resumo de alta hospitalar, o telefone institucional e o Sisreg (Quadro 4).

\section{Utilidade}

A utilidade dos mecanismos de coordenação para uma enfermeira e dois médicos da APS é promover maior fidedignidade às informações sobre as condições de saúde do paciente e possibilidade de construção de conhecimento, enquanto para quatro médicos da $\mathrm{AE}$ facilitavam a comunicação entre os níveis.

\section{Utilização}

Algumas narrativas apresentadas foram ratificadas pela maioria dos atores como obstáculos a utilização dos mecanismos: mau funcionamento do Sisreg, retardando a marcação de consultas na $\mathrm{AE}$ e a transcrição da receita do paciente seguidas vezes; encaminhamentos da APS sem informações clínicas e exames; ausência de reuniões clínicas entre níveis e indisponibilidade para a contrarreferência.

Todos os profissionais de ambos os níveis afirmaram que os mecanismos de referência/ contrarreferência são relevantes, apesar de não utilizados e de preenchimento é incompleto e inadequado.

Todos os médicos da APS narraram que não recebiam contrarreferência e embora realizassem a referência, acreditavam que estas não eram lidas, enquanto cinco médicos da $\mathrm{AE}$ não contra-referiam e não utilizavam os demais me- 
Quadro 4. Aspectos relacionados aos profissionais: mecanismos de coordenação. Recife, 2014/2015.

\begin{tabular}{|c|c|}
\hline $\begin{array}{c}\text { Categorias/ } \\
\text { subcategorias }\end{array}$ & Citações \\
\hline Conhecimento & $\begin{array}{l}\text { "[...] para facilitar... o distrito às vezes faz reunião para discutir [...] para onde são feitos os } \\
\text { encaminhamentos, no sentido de tentar melhorar. [...] aqui na rede nós temos o matricial } \\
\text { (apoio), mas aí vem funcionando mais assim para o lado da parte mental, [...] por conta da } \\
\text { equipe do NASF" (M2-APS). } \\
\text { "A não ser que tenha um internamento, uma coisa mais, aí às vezes a gente tem resumo de alta, } \\
\text { mas não é sempre" (E2-APS). } \\
\text { "Eles [profissionais da APS] mandam, [...] no papel de encaminhamento, mas [...] às vezes não } \\
\text { vem, quase nada, [...] na minha prática não encontro nenhuma, só o papel” (M7-AE). } \\
\text { "Agora estão mandando um, um bilhete, só da regulação [formulário da regulação] [...] não tem } \\
\text { mais [discussão de casos], entre os níveis não, pelo menos aqui" (M8-AE). }\end{array}$ \\
\hline Utilidade & $\begin{array}{l}\text { "[...] eu acho que melhoraria muito, desde que, a gente tivesse o cuidado quando faz o } \\
\text { encaminhamento, [...] com consciência e uma coisa bem legível e que o colega tivesse também a } \\
\text { delicadeza de ler o encaminhamento, [...] e fazer sua referência da mesma maneira [...] seria um } \\
\text { benefício muito grande para paciente" (M2-APS). } \\
\text { "[...] em minha opinião, o impresso facilita porque eu respondo. Então para quem recebe e } \\
\text { também para alguns que mandam para mim, mandam detalhados, assim, os casos. Então eu } \\
\text { acho que isso aí facilita e a comunicação por telefone" (M4-AE). }\end{array}$ \\
\hline Utilização & $\begin{array}{l}\text { "Aí ele (paciente) me diz o que é que o cardiologista fez o que é que o endócrino fez, mas não } \\
\text { porque o endócrino me deu uma contrarreferência. Então a gente nunca recebe, nunca, nunca, } \\
\text { realmente" (M3-APS). } \\
\text { "Se os médicos (da AE) lessem o encaminhamento, por exemplo, eles teriam ideia realmente do } \\
\text { que aquele paciente tem, não teriam que ficar perguntando [...]. Então [...] realmente ajudaria } \\
\text { e evitaria perda de tempo deles [...] seria bom e eu acho que ajudaria o paciente também" (M3- } \\
\text { AB). } \\
\text { "[...] chamou [gestão] assim, no caso os médicos e os enfermeiros para levar casos para serem } \\
\text { discutidos lá em uma reunião [equipe matricial] e essa reunião estava sendo mensal e foi muito } \\
\text { bom porque assim, a gente levava casos complicados que a gente não conseguia dar uma demanda } \\
\text { e na hora discutia-se e as coisas andavam um pouco, eles conseguiam até exames, marcação e } \\
\text { alguns casos a gente conseguiu resolver" (M1-APS). } \\
\text { "[...] porque você chega tem um montão de paciente para você vê [...] não tem como você parar e } \\
\text { conversar com não sei quem, mandar bilhetinho e não sei o que. Porque você não vai ter quando } \\
\text { receber essa resposta de volta" (M6-AE). } \\
\text { "Na realidade eu não tenho muito contato [com os profissionais da atenção primária], porque } \\
\text { o volume de paciente aqui é grande e a gente vai fazendo a demanda. Esse feedback eu sinto que... } \\
\text { que não existe" (M7-AE). } \\
\text { "[...] a contrarreferência não existe. [...] só vem a receita que ele prescreve e tal, quando o } \\
\text { paciente consegue ir" (E1-APS). } \\
\text { "Apoio matricial na rede eu acho que não existe, eles podem até dizer que existe [...]. Eu nunca vi } \\
\text { uma reunião" (M8-AE). } \\
\text { "Então a gente vê que, nem sempre, a informação do paciente é muito confiável, então se a gente } \\
\text { tiver realmente por escrito, vai facilitar. Pode gerar realmente essa questão do tratamento em } \\
\text { duplicidade" (M4-AE). }\end{array}$ \\
\hline
\end{tabular}

canismos, apenas um afirmando que orienta o paciente a mostrar a receita ao médico da APS quando há modificação terapêutica.

\section{Mecanismos informais}

Foi mencionada a utilização do telefone pessoal e da rede social de relacionamento WhatsApp por um médico e uma enfermeira da APS e dois médicos da AE, por vínculos de amizade, para dar seguimento à assistência ao paciente, esclarecer dúvidas, discutir casos e prestar orientações aos profissionais de outros níveis. 
Quadro 4. Aspectos relacionados aos profissionais: mecanismos de coordenação. Recife, 2014/2015.

\begin{tabular}{|c|c|}
\hline $\begin{array}{c}\text { Categorias/ } \\
\text { subcategorias }\end{array}$ & Citações \\
\hline $\begin{array}{l}\text { Mecanismos } \\
\text { informais }\end{array}$ & $\begin{array}{l}\text { "[...] quando há necessidade, eu utilizo exatamente a melhor referência e contrarreferência que } \\
\text { é o celular, eu ligo diretamente para o colega [...] é que funciona muito melhor do que às vezes o } \\
\text { papel, porque às vezes o papel o colega não lê, certo? e quando a gente liga e que se identifica, ele } \\
\text { às vezes se lembra de quem é e a gente conversa sobre aquele paciente [...]" (M2-APS). } \\
\text { "[...] a contrarreferência não existe. [...] só vem a receita que ele prescreve e tal, quando o } \\
\text { paciente consegue ir" (E1-APS). } \\
\text { "[...] o canal da atenção é o whatsapp, [...] enquanto não está sendo cobrado, é o meu método de } \\
\text { me comunicar" (E3-AE). } \\
\text { "[...] tem o pessoal (médicos da APS) que pede para vir, eu acho que é uma forma mais informal, } \\
{[\ldots] \text { aí eles vêm, assim, dois, três ambulatórios ou mais. Aí a gente se conhece, também, e vai }} \\
\text { tirando algumas dúvidas" (M4-AE). } \\
\text { "Eu consigo por amizade no... [unidade de referência] com meus amigos cardiologistas aí eu } \\
\text { consigo, mas pela rede é muito difícil" (M8-AE). } \\
\text { "Aí a gente sempre pede para que ele (paciente) mostre a receita para o outro médico [APS] } \\
{[. . .] \text { veja a mudança que o especialista fez. Que geralmente eles acatam porque geralmente éo }} \\
\text { especialista que está mandando" (M5-AE). }\end{array}$ \\
\hline
\end{tabular}

Nota: APS: Atenção Primária; AE: Atenção Especializada; NASF: Núcleo de Apoio à Saúde da Família.

Fonte: Elaborado pelos autores.

O bilhete (receituário médico) usado para o encaminhamento a outro nível foi referido por três médicos (dois da APS e um AE), que recomendavam aos pacientes que mostrassem aos colegas destinatários.

\section{Discussão}

A trajetória de desvelamento ocorreu pelo exercício de tentar ocupar o lugar de intérpretes hermenêuticos almejando a fusão dos horizontes com os dos entrevistados para apreender o significado sobre o pensar e o agir com relação à coordenação entre os níveis assistenciais. A maioria dos profissionais conhecia as atribuições da coordenação, sem identificar sua execução na rede. O médico da APS não foi reconhecido como responsável clínico pela maioria dos atores nos dois níveis, associado ao desconhecimento de seu papel na visão do especialista, enquanto o da atenção primária ressentia-se. Destacaram-se falhas no uso e preenchimento dos mecanismos de referência/contrarreferência e inexistência de reuniões clínicas, além de entraves organizacionais.

A ênfase à supremacia dos médicos especialistas em detrimento aos da atenção primária, reflete a tradição do ensino e atenção médica fortemente vinculada ao paradigma médico assistencial privatista, gerando a indefinição de papéis e a ampliação dos conflitos na rede de atenção ${ }^{21}$. Para o enfrentamento de problemas que reque- rem atenção e acompanhamento contínuos, o modelo de vigilância à saúde propõe redefinição de políticas e práticas sanitárias, que podem assumir configurações específicas de acordo com a necessidade em saúde organizando processos de trabalho em saúde ${ }^{22}$. O estudo evidenciou transferências recíprocas de responsabilidades entre os médicos da rede pela falha dos mecanismos de referência e contrarreferência, que refletiram graves problemas comunicacionais e de atuação profissional que perpassam juízos de valor, posturas e concepções historicamente determinados ${ }^{21}$.

Sobre o papel da atenção primária, surgiu no discurso da maioria dos participantes deste nível, o reconhecimento da sua autoridade na dimensão autoritativa, "o ser-capaz-de-saber-fazer"19,23 englobando o saber técnico e a práxis da prestação do cuidado em saúde.

Emergiu uma visão parcial dos profissionais da AE do papel do nível primário, restrito ao tratamento precoce ou ao trabalho médico e limitando a ação quanto à possibilidade de resolutividade na/da atuação em equipe. O sentido atribuído foi o de questionamento e de não reconhecimento da autoridade da APS, denotando uma visão de saúde e de cuidado tecnicista limitada à ação em sua dimensão de especialização, separando a doença do ser em sua totalidade, onde o cuidado se presta com a noção de "caso - a parte que lhe cabe"19. A relação não se mostrou dialógica, mas recoberta pela autoconvicção metódica e o autoconceito, visto que se pautou 
em um saber superior (AE) em detrimento ao reconhecimento do outro (APS) na condição de também autoridade, predominando a utilização pelos entrevistados da "arte de curar" na concepção da hermenêutica filosófica ${ }^{19}$.

A indisponibilidade dos profissionais da $\mathrm{AE}$ para o "jogo da conversação" com os colegas da APS revelou-se no seu discurso sobre seu papel enquanto autoridade em saúde, postura compreendida ao se lançar o olhar para os pressupostos gadamerianos de tradição, preconceitos, postura autoritária, não reflexiva e sem a autocrítica genuína ou liberdade crítica $^{18,19,23}$. Evidenciaram-se recorrentemente, entraves para a fusionalidade que oportunizasse o diálogo dos atores em seu projeto contínuo de "vir-a-ser", pela antecipação do horizonte de sentidos que promove a compreensão do "a-ser-compreendido"16,18, a coordenação entre níveis. A "verdade" emergiu pela tradição e saber técnico, em virtude do círculo hermenêutico próprio e inerente para a reabertura de novos significados ter permanecido arraigado à consciência que não se renova pela dialogicidade ${ }^{16,23,24}$.

No horizonte dos profissionais da APS descortinou-se um olhar para si e uma condição de "ser-aí-no-mundo" carregada de descontentamento ou de indignação pelo desrespeito à sua autoridade em saúde. A historicidade própria de sua condição de ser ontológico é violentada pela relação dinâmica com o mundo que se recobre do êxito técnico do médico da $\mathrm{AE}$ e interroga seu sucesso prático ${ }^{23,24}$.

Entrelaçada ao exposto, predominou entre todos os médicos da $\mathrm{AE}$ a postura de não contrarreferenciar, justificada por superlotação do serviço, instrumentos extensos, não objetivos, que apesar de importantes poderiam ser preenchidos pelas enfermeiras ${ }^{3,21,25}$. Igualmente, relatavam não utilizarem as referências do médico da APS por encaminhamentos equivocados. As narrativas dos especialistas manifestaram descrença e desânimo acerca da utilidade dos mecanismos e relacionados ao fluxo de comunicação estabelecido entre os níveis ${ }^{3,25}$.

As falas expressaram repetidamente comportamentos que fragmentam a rede, com consequências negativas para a integralidade da assistência, pois a utilização das informações contidas no formulário de referência contribuiria para diagnósticos mais seguros e coerência no manejo, além de refletirem postura de respeito ao saber do médico da APS, enquanto a contrarreferência o ratificaria ${ }^{15,26}$. Os discursos denunciaram prejuízos ao continuum do cuidado e, concomitante- mente, evidenciaram rupturas da responsabilidade compartilhada entre os níveis que assumiam posturas horizontalizadas e fragmentadas em sua práxis assistencial ${ }^{26,27}$.

A valorização de práticas pautadas em tecnologias duras ou leve-duras em detrimento às le$\mathrm{ves}^{28}$, reveladas pelos informantes especialmente da $\mathrm{AE}$, apontam para o não desenvolvimento da "boa prática" em saúde ${ }^{19,23,24} \mathrm{e}$ que a coordenação foi afetada pela "burocratização da vida" e práticas pouco reflexivas e criativas ${ }^{19,23}$. A sobrevalorização da especialização é arraigada à cultura formativa médica, que representa a tradição nacional, com repercussões no imaginário da sociedade, reafirmando preconceitos à APS.

Mesmo quando os profissionais foram convidados a realizar o exercício da liberdade crítico-reflexiva para questionarem o círculo hermenêutico, houve predomínio da tradição e dos preconceitos, ao atribuírem sentidos à coordenação em saúde e seus aspectos facilitadores ou impeditivos. As narrativas que emergiram não contemplaram uma autocrítica, enquanto partícipes dos serviços ou quanto ao seu lugar de "ser-aíno-mundo" nos distintos níveis de atenção ${ }^{18,19,23}$, retratando estarem presos às suas pré-compreensões e não se revelarem abertos ao diálogo transformador ${ }^{15,16}$.

Os relatos em todas as entrevistas foram permeados de tensão elevada, desmotivação, irritação e desconforto interpessoal interferindo negativamente na relação intersubjetiva dos profissionais de níveis diferentes, mostrando o incipiente exercício da alteridade entre eles, evidenciando-se que não há nessa relação a negociação como postura para compreender a coordenação entre níveis ${ }^{15,29}$. Essa falha no exercício da alteridade foi evidenciada em relação ao paciente, emergindo falas que culpabilizavam os usuários pela piora de suas condiçõos de saúde pela maioria dos profissionais ${ }^{29}$.

A hermenêutica filosófica propõe a abertura para o diálogo produzindo a experiência enquanto estrutura de inversão, vivência da negatividade do que se sabe ou se tem para buscar um ponto de encontro e se chegar a "mutualidade" da conversação genuína que promove transformação ${ }^{15,29}$. O encontro entre os profissionais promoveria maior agilidade, aprimoramento da transferência da informação entre os níveis assistenciais, fortalecimento da coerência da atenção e o seguimento adequado $0^{5,30-32}$.

É importante mencionar o desafio da reescuta de áudios provenientes de entrevistas cujo roteiro não foi idealizado a partir dos pressu- 
postos da hermenêutica filosófica. Apesar disso, procedeu-se um diálogo interpretativo em que se buscou alcançar uma totalidade compreensiva sobre a coordenação entre níveis para se recuperar os elementos que garantissem o círculo hermenêutico, fugindo do relativismo rechaçado por Gadamer. Por outro lado, o limite imposto a este estudo foi minimizado ao se utilizar a mediação conceitual do referencial teórico da coordenação da atenção ${ }^{10-14}$. As limitações estimularam um olhar ainda mais atento para que as categorias da hermenêutica filosófica emergissem, além da triangulação dos pesquisadores para garantir a validade interna ${ }^{20}$.

A indisponibilidade para o "jogo da conversação" e a "fusionalidade" expressas por todos os profissionais mostrou o desconhecimento da autoridade, em seu caráter autoritativo, do médico da APS pelo da AE, sentimento de menos valia do primeiro e postura tecnicista e da "especialização" na práxis de todos, que mostraram seu desejo de domínio da doença pela "arte de curar”. A coordenação entre níveis sob o olhar desses atores se encontra na condição do "aí-a-ser-compreendido", necessitando que eles se lancem no "jogo da compreensão", para que pelo diálogo se construam práticas voltadas ao cuidado integral ${ }^{15,19}$.

A tarefa de se lançar na busca da compreensão sobre o agir e o pensar dos profissionais com respeito aos aspectos expostos não teve por pretensão desvelar os sentidos atribuídos de forma definitiva ou completa, visto que esta se apresentaria como contraditória à essência da hermenêutica filosófica. O horizonte que se utilizou para o círculo da compreensão é exatamente aberto a ressignificações possíveis por novas fusões de horizontes e novas aberturas de sentidos para verdade decorrente da práxis de demais leitores.

\section{Colaboradores}

MCMH Araujo, LCM Vanderlei e MFM Mendes participaram de todas as etapas da autoria do artigo: concepção, planejamento, análise e interpretação dos dados, redação, revisão crítica do conteúdo e aprovação da versão final. PG Frias participou das seguintes etapas da autoria do artigo: concepção, interpretação dos dados, redação, revisão crítica do conteúdo e aprovação da versão final.

\section{Referências}

1. Mendes EV. As redes de atenção à saúde. Brasília: OPAS; 2011.

2. Giovanella L. Redes integradas, programas de gestão clínica e generalista coordenador:análise das reformas recentes do setor ambulatorial na Alemanha. Cien Saude Colet 2011; 16(Supl. 1):1081-1096.

3. Almeida PF, Gérvas J, Freire J, Giovanella L. Estratégias de integração entre atenção primária à saúde e atenção especializada: paralelos entre Brasil e Espanha. Saude Debate 2013; 37(98):400-415.

4. Kuschnir R, Chorny AH. Redes de atenção à saúde: contextualizando o debate. Cien Saude Colet 2010; 15(5):2307-2316.

5. Viana ALA, Bousquat A, Melo GA, Negri FA, Medina MG. Regionalização e Redes de Saúde. Cien Saude Colet 2018; 23(6):1791-1798.

6. Giovanella L, Almeida PF. Atenção primária integral e sistemas segmentados de saúde na América do Sul Cad Saude Publica 2017; 33(Supl. 2):e00118816.

7. Brasil. Ministério da Saúde (MS). Secretaria de Atenção à Saúde. Implantação das Redes de Atenção à Saúde e outras estratégias da SAS. Brasília: MS; 2014.

8. Conill EM, Giovanella L, Almeida PF. Listas de espera em sistemas públicos: da expansão da oferta para um acesso oportuno? Considerações a partir do Sistema Nacional de Saúde espanhol. Cien Saude Colet 2011, 16(6):2783-2794.

9. Mendes EV. Comentários sobre as Redes de Atenção à Saúde no SUS. Divulg Saude Debate 2014; 52:38-49. 
10. Martínez DH, Vázquez Navarrete ML, Vargas Lorenzo I. Factores que influyen en la coordinación entre niveles assistenciales según la opinión de directivos y profesionales sanitários. Gac Sanit 2009; 23(4):280-286.

11. Terraza-Núñez R, Vargas Lorenzo I, Vázquez ML. La coordinación entre niveles asistenciales: una sistematización de sus instrumentos y medidas. Gac Sanit 2006; 20(6):485-495.

12. Vargas I, Mogollón-Pérez AS, De Paepe P, Silva MRF, Unger JP, Vásquez ML. Barriers to health care coordination in market-based and decentralized public health systems: a qualitative study in health care networks of Colombia and Brazil. Health Policy Plan 2016; 31(6):736-748.

13. Vázquez ML, Vargas I, Unger JP, De Paepe P, Mogollón-Pérez AS, Samico I, Albuquerque P, Eguiguren P, Cisneros AI, Rovere M, Bertolotto F. Evaluating the effectiveness of care integration strategies in different health care systems in Latin America: the EQUITY -LA II quasi-experimental study protocol. BMJ Open 2015; 5(7):e007037.

14. Reid R, Haggerty J, Mckendry R. Defusing the confusion: concepts and measures of continuity of health care. Ottawa: Canadian Health Services Research Foundation; 2002.

15. Gadamer HG. Verdade e Método. Petrópolis: Vozes; 2008.

16. Lawn C. Compreender Gadamer. Petrópolis: Vozes; 2018.

17. Missaggia JA hermenêutica em Heidegger e Gadamer: algumas confluências e divergências. Griot Rev Filosof 2012; 6(2):1-13.

18. Ayres JRCM. Para comprender el sentido práctico de las acciones de salud: contribuciones de la Hermenéutica Filosófica. Salud Colect 2008; 4(2):159-172.

19. Gadamer HG. O caráter oculto da saúde. Petrópolis: Editora Vozes; 2006.

20. Minayo MCS. O desafio do conhecimento: pesquisa qualitativa em saúde. 14ª ed. São Paulo: Hucitec; 2014.

21. Vanderlei LCM, Navarrete MLV. Mortalidade infantil evitável e barreiras de acesso a atenção básica no Recife, Brasil. Rev Saude Publica 2013; 47(2):379-389.

22. Teixeira CF, Vilasbôas ALQ. Modelos de atenção à saúde no SUS: transformação, mudança ou conservação. In: Paim JS, Almeida-Filho N, organizadores. Saúde coletiva: teoria e prática. Rio de Janeiro: MedBook; 2014. p. 287-301.

23. Schraiber LB. Quando o 'êxito técnico' se recobre de 'sucesso prático': o sujeito e os valores no agir profissional em saúde. Cien Saude Colet 2011; 16(7):30413042.

24. Gadamer HG. O problema da consciência histórica. $3^{\mathrm{a}}$ ed. São Paulo: Fundação Getúlio Vargas; 2009.

25. Arantes LJ, Shimizu HE, Merchán-Hamann E. Contribuições e desafios da Estratégia Saúde da Família na Atenção Primária à Saúde no Brasil: revisão da literatura. Cien Saude Colet 2016; 21(5):1499-1509.
26. Vargas I, Garcia-Subirats I, Mogollón-Pérez AS, Mendes MFM, Eguiguren P, Cisneros AI, Muruaga M-C, Bertolotto F, Vázquez M-L. Understanding communication breakdown in the outpatient referral process in Latin America: a cross-sectional study on the use of clinical correspondence in public healthcare networks of six countries. Health Policy Plan 2018; 33:494-504.

27. Macedo LM, Martin STF. Interdependência entre os níveis de atenção do Sistema Único de Saúde (SUS): significado de integralidade apresentado por trabalhadores da Atenção Primária. Interface (Botucatu) 2014; 18(51):640-660.

28. Merhy EE, Feuerwerker LCM. Novo olhar sobre as tecnologias de saúde: uma necessidade contemporânea. In: Merhy EE, Baduy RS, Seixas CT, Almeida DES, Slomp Júnior H. Avaliação compartilhada do cuidado em saúde: surpreendendo o instituído nas redes. $1^{\mathrm{a}} \mathrm{ed}$. Rio de Janeiro: Hexis; 2016. p. 59-72.

29. Araújo JL, Paz EPA, Moreira TMM. Hermenêutica e saúde: reflexões sobre o pensamento de Hans-Georg Gadamer. Rev Esc Enferm USP 2012; 46(1):200-207.

30. Jesus RPFS, Espírito Santo ACG, Mendes MFM, Samico IC. Health care professional's perceptions of coordination between levels of care in two large municipalities in the State of Pernambuco, Brazil. Interface (Botucatu) 2018; 22(65):423-434.

31. Scholze AS, Duarte Junior CF, Silva YF. Trabalho em saúde e a implantação do acolhimento na atenção primária à saúde: afeto, empatia ou alteridade? Interface (Botucatu) 2009; 13(31):303-314.

32. Veras RP, Caldas CP, Motta LB, Lima KC, Siqueira RC, Rodrigues RT, Santos LM, Guerra AC. Integration and continuity of Care in health care network models for frail older adults. Rev Saude Publica 2014; 48(2):357365.

Artigo apresentado em 17/12/2019

Aprovado em 23/06/2020

Versão final apresentada em 25/06/2020

Editores-chefes: Romeu Gomes, Antônio Augusto Moura da Silva 